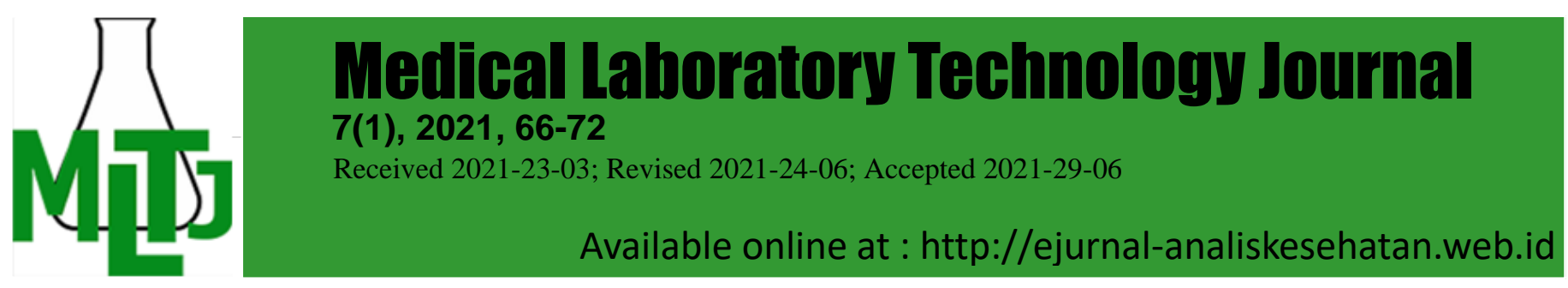

\title{
The Use of High Resolution Melting (HRM) Method to Detect rs1800629 of Tumor Necrosis Factor-alpha (TNF-alpha) Gene among Tuberculosis Patients
}

\author{
*Kinasih Prayuni', Intan Razari², Silviatun Nihayah², Rika Yuliwulandari1,3
}

${ }^{1}$ Genetic Research Center, YARSI Research Institute, YARSI University, Indonesia ${ }^{2}$ YARSI Research Institute, YARSI University, Indonesia ${ }^{3}$ Department of Pharmacology

Faculty of Medicine, YARSI University, Indonesia.

*Email : kinasih.prayuni@yarsi.ac.id

DOI: 10.31964/mltj.v7i1.362

\begin{abstract}
The rs1800629 polymorphism plays a crucial role in the pathogenesis of infectious and autoimmune diseases. Meanwhile, tuberculosis (TB) remains a health primary infectious disease in Indonesia. The purpose of this study is to evaluate the HRM method in detecting the rs 1800629 genotype, in the TNF- $\alpha$ gene's promoter region, within TB patients. The benefit of this study is to accelerate the detection of rs 1800629 with a simple, rapid, and cost-effective method for genotyping and mutation screening that does not include the use of a fluorescent probe. In this experimental study, the rs1800629 genotyped in a total of 25 tuberculosis patients using KAPA HRM kit in MyGo Mini PCR, and all amplified PCR products subsequently dispatched for direct DNA sequencing to Macrogen Inc, South Korea. Based on the results, a 100\% concordance find in the genotyping of rs 1800629 between HRM and sequencing. The authors provided evidence to use HRM in detecting rs 1800629 within the TNF- $\alpha$ promotor region. This application as a genotyping assay in tuberculosis patients is a low-cost, rapid, and accurate detection. However, further studies using the HRM method in case-control samples of tuberculosis are required to evaluate the method's effectiveness and to obtain more information regarding the genotype's susceptibility to tuberculosis and its adverse effect treatment, including anti-tuberculosis drug, induced liver injury (AT-DILI), and multidrugresistant TB (MDR-TB), within the Indonesian population.
\end{abstract}

Keywords: High resolution melting; genotyping; TNF- $\alpha$ gene; tuberculosis; rs1800629

\section{INTRODUCTION}

Tumor necrosis factor-alpha (TNF- $\alpha$ ) is a human leukocyte antigen system gene located on the 6p21 chromosome, in the class III region major histocompatibility complex (Yang et al., 2014; Aboutorabi et al., 2018). However, the most studied polymorphism is TNF- $\alpha(-308 \mathrm{~A} / \mathrm{G})$ rs1800629, found in the promoter region. The transition from $\mathrm{G}$ to $\mathrm{A}$ within the promoter at position -308 is associated with the TNF- $\alpha$ levels (Elahi et al., 2009; $\mathrm{Li}$ et al., 2013). Alteration in these levels has a possible influence on the immune response to pathogens and a contribution to disease susceptibility in individuals (Elahi et al., 2009; Qidwai and Khan, 2011).

In addition, the rs 1800629 polymorphism has a crucial role in infectious and autoimmune disease pathogenesis (Qidwai and Khan, 2011). According to previous studies show that these polymorphism are associated with asthma (Yang et al., 2014), 
Osteoarthritis (Chen et al., 2018), celiac disease (Khan et al., 2016), and infectious diseases, including leprosy and tuberculosis (Qidwai and Khan, 2011). Tuberculosis remains a significant contagious disease globally, and Indonesia is known as the country with the second-highest TB cases (World Health Organization (WHO), 2020). A previous study showed an association between rs1800629 and tuberculosis (Wu et al., 2019), but another study showed a contrary result (Qidwai and Khan, 2011). However, these polymorphisms are worth studying because a different study reported rs1800629 to significantly correlated with anti-tuberculosis drug induced liver injury (AT-DILI) (Kim et al., 2012), the most prevalent adverse reaction in tuberculosis treatment (Chen et al., 2015). Due to rs1800629's important role, there is a need to develop a reliable and lowcost technique to detect the polymorphism.

The HRM (High-resolution melting curve) analysis is a potential method for rapid genotyping and a high-throughput technique for conducting genetic variation screening and scanning for mutation in disease-related genes, using the double-stranded DNA's melting profile (Chen et al., 2014; Islam et al., 2018). In addition, the technique uses a fluorescent DNA binding dye for genotyping, as opposed to expensive labeled probes. In the presence of saturated DNA binding dye concentrations, a reduction in fluorescence intensity occurs as the double-stranded DNA becomes single stranded, following a temperature rise and dye release (Graham et al., 2005). The HRM analysis allows researchers to detect and locate mutations rapidly and identify novel genetic variants without any post-PCR handling, for instance, sequencing or electrophoresis (Islam et al., 2018).

To the best of our knowledge, no published study evaluates the HRM analysis to detect rs1800629 for TB patient screening. Additionally, another method, such as Taqman genotyping assay, is expensive. Another way, such as combining conventional PCR and DNA sequencing as a standard gold method for SNP genotyping, is more laborious and time-consuming. Therefore, this study evaluates the HRM technique's effectiveness in detecting rs1800629 polymorphism within the TNF alpha gene in TB patients, which can apply in clinical settings.

\section{MATERIALS AND METHOD Sample Collection}

This is an experimental study involving 25 tuberculosis patients from Pasar Rebo Hospital, Jakarta, Indonesia. Before the experiment, all participants filled and submitted consent forms. Subsequently, $3 \mathrm{~mL}$ of peripheral venous blood collects with EDTA as an anticoagulant (BD Vacutainer) and stored in $\mathrm{a}-20^{\circ} \mathrm{C}$ freezer until further processing.

\section{DNA Extraction}

Genomic DNA extracted with a Maxwell RSC Whole Blood DNA kit (Promega) in Maxwell automatic nucleic acid instrument (Promega) according to the manufacturer's instructions from each blood sample, The quantity, and quality of DNA then calculated using NanoQuant Plate (Tecan) before amplification and HRM analysis.

\section{Amplification and HRM Analysis}

The rs1800629 variants were amplified in a MyGo Mini Real-Time PCR System (MyGoPCR). A $20 \mu \mathrm{l}$ total volume PCR reaction mixture was prepared by adding ten $\mu \mathrm{l}$ KAPA HRM Master Mix, one $\mu \mathrm{l}$ of $10 \mathrm{ng}$ genomic DNA, $0.6 \mu \mathrm{l}$ of $10 \mu \mathrm{M}$ forward primer and $0.6 \mu \mathrm{l}$ of $10 \mu \mathrm{M}$ reverse primers, two $\mu \mathrm{l}$ of $\mathrm{MgCl} 2$ (KAPA HRM Fast, KAPA BioSystem) 
and $5.8 \mu \mathrm{l}$ of Nucleus Free Water (NFW). Furthermore, the PCR thermocycling profile included one cycle denaturation at $95^{\circ} \mathrm{C}$ for 5 min, 45 cycles denaturation at $95^{\circ} \mathrm{C}$ for 10 $\mathrm{s}$, annealing and extension at $60^{\circ} \mathrm{C}$ for $30 \mathrm{~s}$, and an HRM step from $60^{\circ} \mathrm{C}$ to $95^{\circ} \mathrm{C}$, rising at $0.2^{\circ} \mathrm{C}$. Also, forward and reverse primer selection was performed using the Primer3 software (CA, USA), synthesized by Macrogen Inc. (South Korea). The primer sequences were 308F3: 5'-CACAGACCTGGTCCCCAAAA-3' and 308R5: 5'CATCCTCCCTGCTCCGATTC-3', and the primers targeted the TNF- $\alpha$ gene's 136 bp long, near the rs1800629 variant.

The HRM data analysis conducts with the MyGo Mini PCR software supplied with the instrument and distinguishing sequence variations based on different normalized and temperature-shifted melting curve shapes. Sequencing analyses were also conducted in all 25 samples to confirm the HRM assay genotyping data's quality and accuracy. In addition, purification of HRM amplicons was carried out with a gel purification kit before dispatch for direct DNA Sequence by Macrogen Inc., South Korea. This study received approval from YARSI University's Ethics Committees, with 049/KEP-UY/BIA/V/2020.

\section{RESULTS AND DISCUSSION}

Based on the previous study, rs1800629 in the TNF- $\alpha$ promoter region is associated with autoimmune and infectious disease, including asthma (Yang et al., 2014), Osteoarthritis (Chen et al., 2018), celiac disease (Khan et al., 2016), and infectious disease, such as leprosy and tuberculosis (Qidwai and Khan, 2011). Currently, tuberculosis and adverse effect treatments are a significant problem in Indonesia (World Health Organization(WHO), 2020). In the inflammatory response against tuberculosis, TNF- $\alpha$ acts as an essential mediator (Sivangala et al., 2014). The antigen system gene also plays a critical role in drug-induced immune responses, with a possible influence on AT-DILI incidence (anti-tuberculosis drug-induced liver injury) (Bao et al., 2018).

A previous study showed rs 1800620 and association to tuberculosis is inconsistent within the population. Wu et al. (2019) reported rs 1800629 associated with tuberculosis in the Tibetan but not in the Han Chinese population (Wu et al., 2019). Meanwhile, Bikmaeva et al. (2002) showed an association between the ' $A$ ' allele and risk of pulmonary tuberculosis within the Russian population (Bikmaeva et al., 2002). Scola et al. (2003) reported reduced low-producer GG homozygous individuals in Caucasian TB patients (Scola et al., 2003). However, several studies stated no association between rs1800629 and risk of tuberculosis within the Southern and Northern Indian populations and Thai and Turkish people (Qidwai and Khan, 2011; Sivangala et al., 2014). Thus, there is a need to develop a reliable and low-cost technique to detect polymorphism, considering rs1800629's crucial role.

According to Figure 1, three genotypes for TNF- $\alpha$ rs1800629 SNP were distinguished. The homozygote GG's Tm value (approximately $87.5^{\circ} \mathrm{C}$ ) experienced a left shift compared to the homozygote AA $\left(86^{\circ} \mathrm{C}\right)$ due to the $\mathrm{GC}$ base pair present a higher melting temperature, compared to the AT base pair. Furthermore, the heterozygote AG's temperature-shifted melting peak occurred between homozygotes $A A$ and $G G\left(87^{\circ} \mathrm{C}\right)$. 


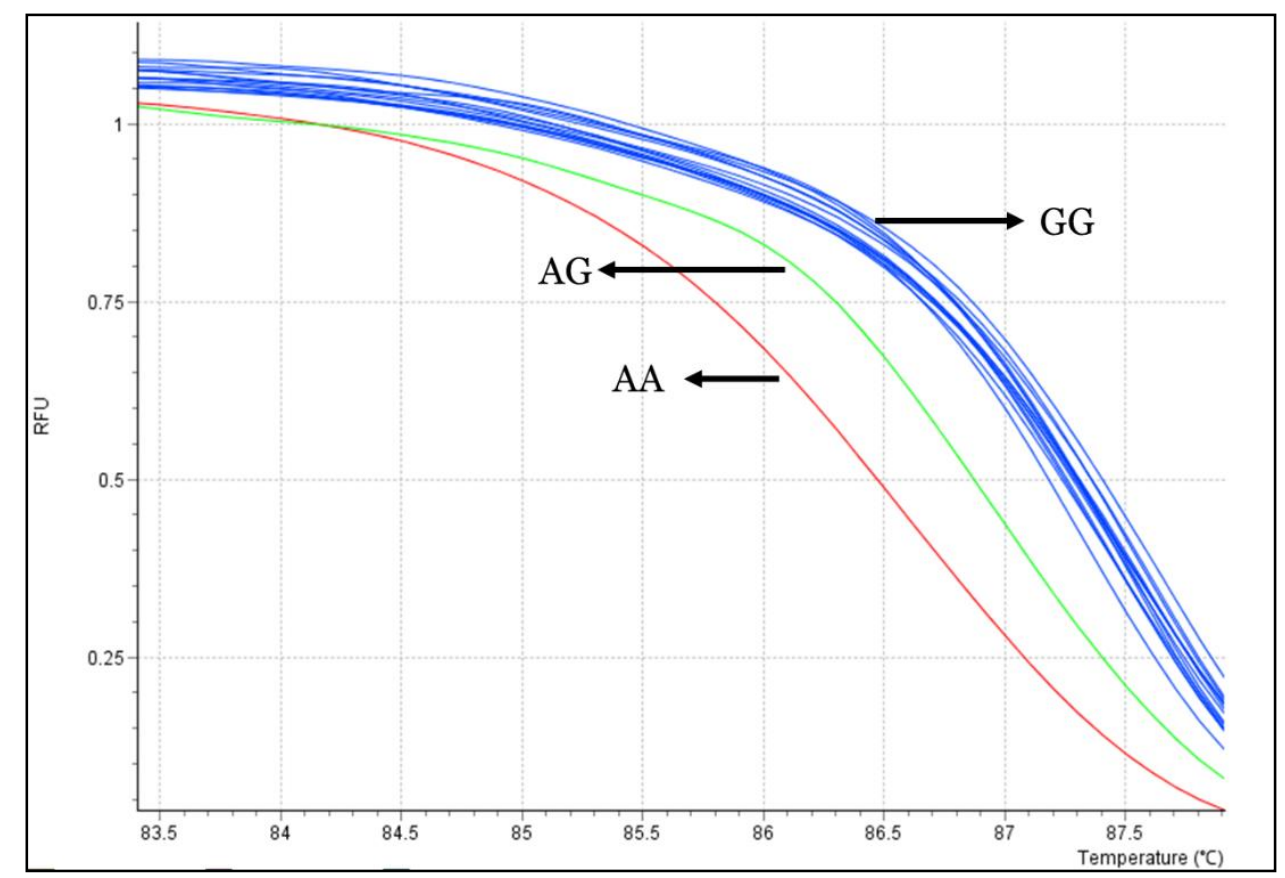

Figure 1. Normalized graphs for HRM of rs1800629.

The primer in this study successfully detected the rs1800629 genotype. Primer design, reaction components, and cycling conditions are critical components of a successful HRM assay (Tucker and Huynh, 2014). In this study, the primer designed to target the PCR product $136 \mathrm{bp}$, from TNF-a gene amplification, and the product size are sufficient for HRM assay based on Tucker \& Huynh, 2014. A PCR product above 500 bp decreases the sensitivity and makes analysis difficult due to gradual melting and variant detection disruption (Słomka et al., 2017). However, several studies suggested an amplicon size below 100 bp allows for increased analysis accuracy. The reduction in amplicon results in increased melting temperature differences, and consequently, improved differentiation (Erali, Voelkerding, and Wittwer, 2008; Słomka et al., 2017).

Figure 2 shows the TNF- $\alpha$ rs1800629 polymorphism's sequencing result. Direct DNA sequencing as a gold standard for SNP genotyping showed representing rs 1800629 GG and AA genotypes. All the 25 samples used to optimize the HRM method showed concordance results between HRM and sequencing results. A $100 \%$ concordance observed while comparing rs 1800629 HRM genotyping to the effects of DNA sequencing. This result proved HRM method could detect and differentiate genotype in rs1800629. Therefore, this low-cost, easy, and high sensitivity/ specificity technology ought to apply in detecting other variants within the TNF- $\alpha$ gene. A previous study showed that discordance results between HRM and Sanger sequencing methods could be found due to low-quality DNA samples (Do and Dobrovic, 2009). Low-quality DNA may produce nonspecific PCR products, resulting in incorrect scoring of results in HRM analyses, or failed reactions that also affected validation result using Sanger Sequencing (Applied Biosystem, 2010) 


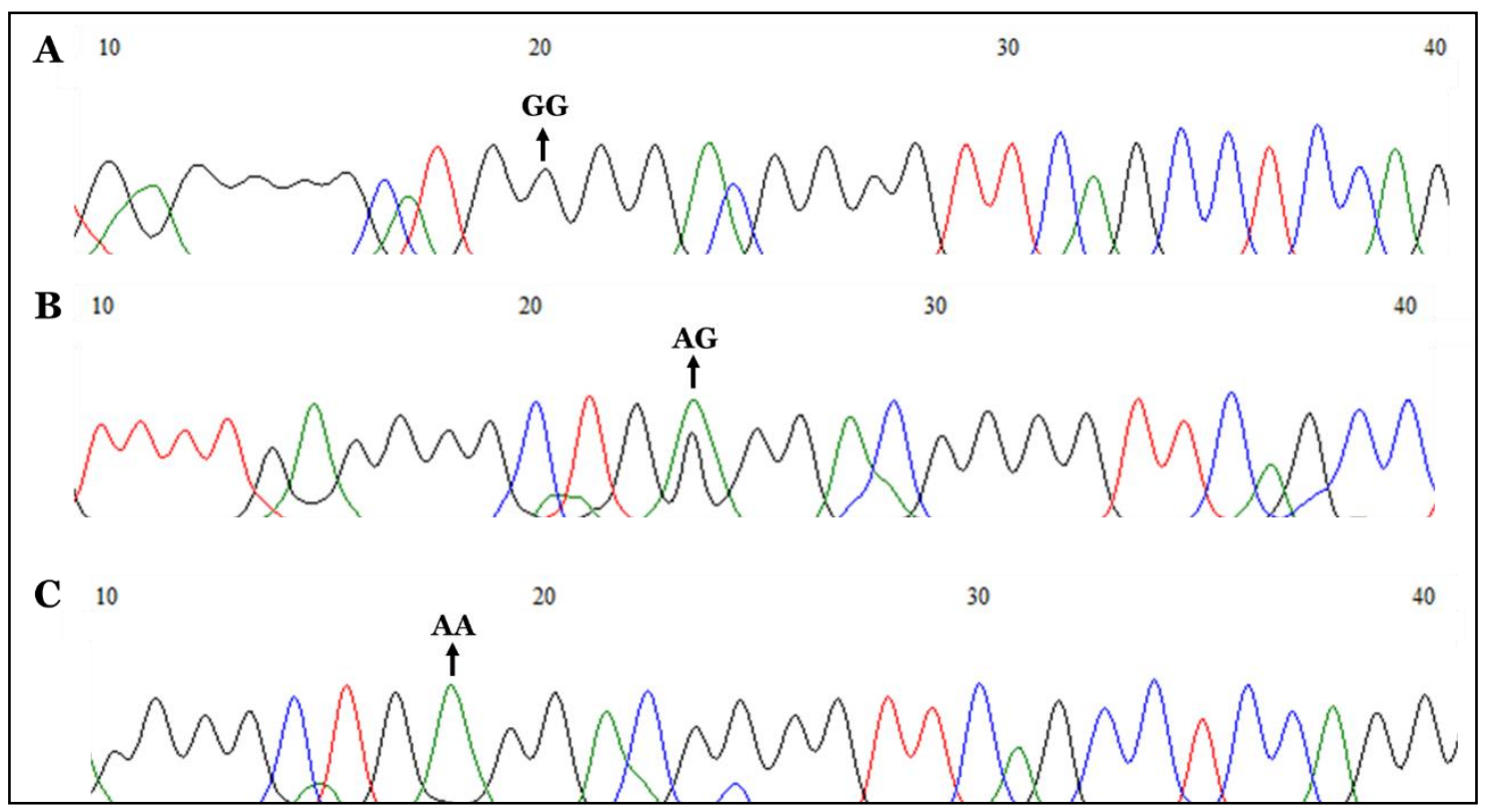

Figure 2. Different rs1800629 Polymorphism Genotypes from Sequencing Result (A representing GG genotype; B representing AG genotype; C representing AA genotype)

The HRM assay presents several benefits compared to other molecular methods. Firstly, the technique is fast and straightforward, as the melting analysis and amplification, and melting analysis are performed as one procedure, on a real-time PCR device, in this case, a MyGo Mini PCR system. Secondly, the potential risk of cross-contamination reduces because this assay conduct in one closed tube. Lastly, there is no need for expensive specialized reagents or fluorescent probes. In addition, no post PCR handling is required, including electrophoresis and sequencing.

However, this study faced several limitations. First, This study only uses 25 samples to evaluate the use of the HRM method in detecting rs1800629. Therefore, further studies involving more models are required to examine the differences of genotypes in rs1800629, using the HRM method. A case-control study using the HRM method in tuberculosis cases is also necessary to evaluate the method's effectiveness and obtain more information on rs 1800629 susceptibility to tuberculosis and tuberculosis adverse effect treatment, including AT-DILI and MDR-TB, in the Indonesian population. Second, HRM analysis is not suitable for amplicons containing two or more SNPs. The sensitivity of mutation scanning may decrease by producing complex melting curve data, and a different genotyping strategy had to be applied. Therefore, it is crucial to design a suitable primer with optimum length. Third, although HRM analysis is rapid and costeffective, Sanger sequencing may be required to confirm the variants from samples that failed to detect using HRM analysis.

\section{CONCLUSION}

This study provided evidence to use the HRM method in detecting rs 1800629 genotype within the TNF- $\alpha$ promotor region. According to the study, applying HRM as a genotyping assay in tuberculosis patients to detect rs 1800629 genotype is a low-cost, rapid, and accurate technique. Further study with larger samples needs to examine the 
differences of genotypes in rs1800629 using the HRM method to test for sensitivity and specificity before being applied in clinical settings.

\section{ACKNOWLEDGEMENT}

The authors are grateful to YARSI University for the provision of an Internal Grant (grant no. 164/INT/UM/WRII/UY/XI/2019) towards this study, as well as to YARSI Foundation and the study participants, for supporting and partaking in this research, respectively.

\section{CONFLICT OF INTEREST}

None of the authors have any conflicts of interest to declare in relation to this work

\section{REFERENCE}

Aboutorabi, R., Behzadi, E., Sadegh, M. J., Fatehi, S. P., Semsarzadeh, S., Zarrin, Y., ... Mostafavi, F. S. (2018). The study of association between polymorphism of TNF- $\alpha$ gene's promoter region and recurrent pregnancy loss. Journal of Reproduction and Infertility, 19(4), 211-218.

Applied Biosystem. (2010). A Guide to High Resolution Melting ( HRM ) Analysis. Foster City, CA, USA.

Bao, Y., Ma, X., Rasmussen, T. P., \& Zhong, X. B. (2018). Genetic Variations Associated with Anti-Tuberculosis Drug-Induced Liver Injury. Current Pharmacology Reports, 4(3), 171-181. https://doi.org/10.1007/s40495-018-0131-8

Bikmaeva, A. R., Sibiryak, S. V., Valiakhmetova, D. K., \& Khusnutdinova, E. K. (2002). Polymorphism of the tumour necrosis factor alpha gene in patients with infiltrative tuberculosis and from the Bashkortostan populations. Molecular Biology, 36, 631633.

Chen, C., Li, S., Lu, X., Tan, B., Huang, C., \& Qin, L. (2014). High resolution melting method to detect single nucleotide polymorphism of VKORC1 and CYP2C9. International Journal of Clinical and Experimental Pathology, 7(5), 2558-2564.

Chen, J., Wu, Y., Yu, J., \& Shen, J. (2018). Association between tumor necrosis factor alpha rs1800629 polymorphism and risk of osteoarthritis in a Chinese population. Brazilian Journal of Medical and Biological Research, 51(8), e7311. https://doi.org/10.1590/1414-431X20187311

Chen, R., Wang, J., Zhang, Y., Tang, S., \& Zhan, S. (2015). Key factors of susceptibility to anti-tuberculosis drug-induced hepatotoxicity. Archives of Toxicology, 89(6), 883897. https://doi.org/10.1007/s00204-015-1473-1

Do, H. and Dobrovic, A. (2009). Limited copy number - high resolution melting (LCN$\mathrm{HRM}$ ) enables the detection and identification by sequencing of low level mutations in cancer biopsies. Molecular Cancer, 8, 82. doi: 10.1186/1476-4598-8-82.

Elahi, M. M., Asotra, K., Matata, B. M., \& Mastana, S. S. (2009). Tumor necrosis factor alpha - 308 gene locus promoter polymorphism: An analysis of association with health and disease. Biochimica et Biophysica Acta - Molecular Basis of Disease, 1792(3), 163-172. https://doi.org/10.1016/j.bbadis.2009.01.007

Erali, M., Voelkerding, K. V., \& Wittwer, C. T. (2008). High Resolution Melting Applications for Clinical Laboratory Medicine. Exp Mol Phatol, 85(1), 50-58. https://doi.org/10.1016/j.yexmp.2008.03.012.High 
Graham, R., Liew, M., Meadows, C., Lyon, E., \& Wittwer, C. T. (2005). Distinguishing Different DNA Heterozygotes by High- Resolution Melting. Clinical Chemistry, 51(7), 1295-1298. https://doi.org/10.1373/clinchem.2004.046466

Islam, M. T., Sarkar, S. K., Sultana, N., Begum, M. N., Bhuyan, G. S., Talukder, S., ... Mannoor, K. (2018). High resolution melting curve analysis targeting the HBB gene mutational hot-spot offers a reliable screening approach for all common as well as most of the rare beta-globin gene mutations in Bangladesh. BMC Genetics, 19(1), 1-12. https://doi.org/10.1186/s12863-017-0594-3

Khan, S., Mandal, R. K., Jawed, A., Dar, S. A., \& Wahid, M. (2016). TNF- $\alpha-308$ G > A (rs1800629) Polymorphism is Associated with Celiac Disease: A Meta-analysis of 11 Case-Control Studies. Scientific Reports, 6, 32677. https://doi.org/10.1038/srep32677

Kim, S. H., Kim, S. H., Yoon, H. J., Shin, D. H., Park, S. S., Kim, Y. S., ... Jee, Y. K. (2012). TNF-a genetic polymorphism -308G/A and antituberculosis drug-induced hepatitis. Liver International, 32(5), 809-814. https://doi.org/10.1111/j.14783231.2011.02697.x

Li, M., Han, Y., Wu, T., Feng, Y., \& Wang, H. (2013). Tumor Necrosis Factor Alpha rs1800629 Polymorphism and Risk of Cervical Lesions : A Meta-Analysis. PlosOne, 8(8), e69201. https://doi.org/10.1371/journal.pone.0069201

Qidwai, T., \& Khan, F. (2011). Tumour Necrosis Factor Gene Polymorphism and Disease Prevalence. Scandinavian Journal of Immunology, 74, 522-547. https://doi.org/10.1111/j.1365-3083.2011.02602.x

Scola, L., Crivello, A., Marino, V., Gioia, V., Serauto, A., Candore, G., ... Lio, D. (2003). IL-10 and TNF-alpha polymorphisms in a sample of Sicilian patients affected by tuberculosis: implication for ageing and life span expectancy. Mech Ageing Dev, 124(4), 569-572.

Sivangala, R., Ponnana, M., Thada, S., Joshi, L., Ansari, S., Hussain, H., ... Gaddam, S. (2014). Association of Cytokine Gene Polymorphism in Patients with Tuberculosis and Their Houshold Contacs. Human Immunology, 79, 197-205.

Słomka, M., Sobalska-Kwapis, M., Wachulec, M., Bartosz, G., \& Strapagiel, D. (2017). High resolution melting (HRM) for high-throughput genotyping-limitations and caveats in practical case studies. International Journal of Molecular Sciences, 18(11). https://doi.org/10.3390/ijms 18112316

Tucker, E. J., \& Huynh, B. L. (2014). Genotyping by high-resolution melting analysis. Methods in Molecular Biology, 1145(3), 59-66. https://doi.org/10.1007/978-1-49390446-4 5

World Health Organization(WHO). (2020). Global Tuberculosis Report 2020. Geneva.

Wu, S., Wang, M. G., Wang, Y., \& He, J. Q. (2019). Polymorphisms of cytokine genes and tuberculosis in two independent studies. Scientific Reports, 9(1), 1-11. https://doi.org/10.1038/s41598-019-39249-4

Yang, G., Chen, J., Xu, F., Bao, Z., Yao, Y., \& Zhou, J. (2014). Association between Tumor Necrosis Factor-a rs1800629 Polymorphism and Risk of Asthma: A MetaAnalysis. PlosOne, 9(6), e99962. https://doi.org/10.1371/journal.pone.0099962 